\title{
GUARDIÃS DO PASSADO: A POESIA COMO SALVAGUARDA DA MEMÓRIA DO PACÍFICO NA ANTOLOGÍA DE MUJERES POETAS AFROCOLOMBIANAS
}

Julián Vivas Banguera Valéria Amim

Resumo: A poesia afro que nasce na costa do Pacífico colombiano está ancorada nas mulheres que salvaguardam em suas narrativas o passado de seus povos e desafiam o silenciamento a que foram historicamente submetidas pelo sistema-mundo patriarcal e racista de Occidente. Esta pesquisa qualitativa, de cunho bibliográfico, visa identificar os elementos da memória coletiva (NORA, 1993; CANDAU, 2018) das comunidades negras do Pacífico colombiano presentes na Antologia de Mulheres Poetas Afro-Colombianas (2010), a mais "abrangente e completa" compilação de escritoras afro-colombianas do último século. Nesse sentido, focaremos nosso olhar em analisar, a partir das teorias de N'gom (2015) e Freja de la Hoz (2010), como as poetas reescrevem a história de suas comunidades e usam a literatura como método de "reexistência" que ajuda a fertilizar novos discursos de identidade sobre o que significa ser "Afro-Pacífico". Além disso, o texto examina como, em diálogo com o feminismo negro (LUGONES, 2008; AKOTIRENE, 2019), as "autoras-povo" denunciam em seus versos as opressões do sistema sexo/gênero que ainda subjuga as feminilidades da diáspora africana.

Palavras chave: Poesía. Memória. Afro-colombianos. Identidad. feminismo negro.

Abstract: The black poetry that is born on the Colombian Pacific coast is anchored in women who safeguard in their narratives the past of their communities and defy the silencing to which they have historically been subjected by the occidental patriarchal and racist world-system. This qualitative research, of bibliographic nature, aims to identify the elements of the collective memory (NORA, 1993; CANDAU, 2018) of the black communities of the Colombian Pacific present in Antologia de Mulheres Poetas Afro-Colombianas (2010), the most "comprehensive and complete" compilation of Afro-Colombian writers from the last century. In this sense, we will focus our gaze on 
analyzing, based on the theories of N'gom (2015) and Freja de la Hoz (2010), how the poets rewrite the history of their communities and use literature as a method of "re-existence" which helps to fertilize new identity discourses about what it means to be "Afro-Pacific". Furthermore, the text examines how, in dialogue with Black Feminism (LUGONES, 2008; AKOTIRENE, 2019), the "authors-people" denounce in their verses the oppressions of the sex/gender system that still subjugates the femininities of the African diaspora.

Keywords: Poetry. Memory. Afro-Colombians. Identity. Black Feminism.

\section{MEMÓRIA COLETIVA E LITERATURA ORAL AFRO-COLOMBIANA}

As mulheres negras têm sido historicamente as principais guardiãs da memória coletiva das comunidades negras do Pacífico colombiano. Em seus poemas, desafiam o silenciamento hegemônico de que historicamente foram vítimas para esculpir poemas nos quais narram suas histórias de vida, questionam a realidade histórico-social de seus povos e reformulam o discurso identitário sobre o que significa nascer com a pele escura nesta região esquecida do país.

O especialista em estudos da literatura afro-hispânica, Alain Lawo-Sukam (2011) explica que desde os tempos sangrentos da escravidão, as crianças da diáspora africana na Colômbia usavam poesias e canções para salvaguardar a memória, a cultura africana, aliviar as tristezas diárias e desafiar o jugo da opressão. Assim, a palavra rimada tornouse uma das principais ferramentas que Ihes permitiram, 
além de preservar o legado de seus ancestrais, "reaccionar instintivamente ante el terror, el dolor, la flagelación y la prisión" do sistema colonizador (ZAPATA, 1989, p. 96).

Nas comunidades negras do Pacífico colombiano as tipologias e composições próprias da literatura oral são criadas para serem disseminadas oralmente por meio de uma cadeia de transmissores, depositários e, ao mesmo tempo, recriadores da visão do passado compartilhada por membros de uma mesma população (PRADO, 1996, p. 193):

Cuando hablo de literatura oral, hablo de un cuerpo de memoria colectiva, de un archivo donde se fundamenta el complejo de nuestra identidad. Es la visión de la comunidad, la trasmisión, la posibilidad de hablar y escuchar en el mismo código. Es el conjunto de formas en las que se expresa un sector de la oralidad de un pueblo. Es su conocimiento, su sabiduría. (PRADO, 1996, p. 193)

Nesse sentido, quando falamos de memória coletiva, referimo-nos àquela construção de imagens, que, segundo o historiador francês Pierre Nora, está sempre em "permanente evolução, aberta à dialética da lembrança e do esquecimento, inconsciente de suas deformações sucessivas, vulnerável a todos os usos e manipulações, susceptível de longas latências e de repentinas revitalizações" (1993, p. 10). E é nesse quadro que a narrativa, a poesia e outros gêneros literários têm 
atuado historicamente como suportes para o diálogo com as imagens que configuram a memória, graças ao seu caráter confessional e rememorativo inato (PEREIRA, 2014).

Consequentemente, o resgate da memória coletiva e a celebração da identidade afro-colombiana se tornaram, independentemente das diferenças geracionais, o principal eixo temático da obra dos escritores afro-colombianos. No entanto, acrescenta Lawo-Sukam, essa inclinação costuma ser justaposta ao "deseo vehemente de denunciar las duras condiciones de vida del pueblo afro-colombiano y abogar por una mayor y más incluyente humanidad" (2011, p. 41).

Nas palavras do especialista em literatura latinoamericana, Hugo Achugar (2006), o apelo à memória coletiva na literatura também permitiu às comunidades filhas da diáspora africana na América, reescreverem os discursos históricos hegemônicos do sistema colonial e se tornarem as narradoras de seus próprios mundos. Nessa ordem de ideias, narrar a memória também implica "resgatar os esquecimentos que haviam sido submetidos indivíduos, obras e fatos históricos" (ACHUGAR, 2006).

E essa tentativa de reescrever a realidade sobre seus mundos negros também é lida na literatura de mulheres afro-colombianas que desafiaram o silenciamento do 
sistema racista e patriarcal para denunciar que ele, ainda, subjuga as feminilidades da diáspora africana, desumanizando-as, negando-Ihes o acesso aos seus direitos sociais e as proibindo de serem donas inalienáveis de seus corpos, sentimentos e desejos. A isso se acrescenta que as ideais de gênero introduzidas pelo Ocidente nas populações catequizadas (ameríndios) e escravizadas (africanos e ameríndios) pela e para a colonização, também forçaram as mulheres a cruzarem um caminho íngreme e rochoso se quiserem se tornar escritoras (LUGONES, 2008).

Carolina Alzate mostrou como a sociedade patriarcal colombiana excluiu e desacreditou durante o século XIX, toda a literatura que não foi escrita por homens brancos burgueses e heterossexuais:

Las mujeres podían escribir, y de hecho escribían; pero se trataba de una escritura de tema doméstico y que no buscaba ni esperaba circulación pública: una escritura hecha desde y para el espacio del hogar. Tampoco se promovía cualquier género entre las mujeres, únicamente la poesía, pero una poesía a la cual no se le exigía calidad literaria, y de la cual, si aparecía, se desconfiaba. Por esto poetisa no es lo mismo que poeta, no es simplemente el femenino de poeta: estas eran poetisas. $(2004$, p. 277$)$

A citação apresentada no parágrafo acima assume muito mais relevância se entendermos que somente até o final do 
século passado, todas as mulheres negras que escreviam poesia eram classificadas pelo status quo literário colombiano, como poetisas, diminuindo, desde o início, a capacidade de produção das autoras, reconhecendo parcialmente um certo nível de literariedade. Soma-se a isso o fato de que durante muito tempo a literatura afrocolombiana só foi sinônimo de produções de autores negros como Candelario Obeso, Arnaldo Palácios, Carlos Arturo Truque, Helcías Martan Góngora, Hugo Salazar Valdés, Jorge Artel e Manuel Zapata Olivella.

M'bare N'gom esclarece que a pesada cortina que ocultava a existência de uma literatura escrita por mulheres afro-colombianas, só foi desmontada no final do século XX:

Si bien hubo iniciativas de divulgación de los procesos creativos de la mujer en Colombia, la autora afrocolombiana ha sido, por decirlo de alguna forma, la convidada de piedra. En 1975, Eddy Torres publica Poesía de autoras colombianas, una antología que recoge las selecciones de siete poetas del periodo colonial y republicano y treinta autoras contemporáneas entre 1901 y 1975 . No recoge ni menciona la presencia afrocolombiana (ctd en Cuesta, 13). En 1995, Teresa RozoMoorhouse saca la antología Diosas en bronce, la cual incluye a tres poetas afrocolombianas de un total de 97: Nadhyma Triana (1932), María Teresa Ramírez (1944) y Ana Milena Lucumi (1964). (N'GOM, 2015, p. 125) 
Depois de colocar a lupa sobre a literatura afrocolombiana do século XX, Guiomar Cuesta Escobar e Alfredo Ocampo Zamorano concluíram que das oito antologias poéticas publicadas naquele período, apenas em duas aparecem autoras afro-colombianas (2010): Antología 21 años de poesía colombiana (1942-1963) e Diosas en bronce; Poesía contemporánea de la mujer colombiana (1995). Um século depois, a realidade não é tão diferente, apenas três grandes antologias com composições de autoras negras foram publicadas: La palabra poética del afrocolombiano (2001), ¡Negras somos! Antología de 21 mujeres poetas afrocolombianas de la Región Pacífica (2008) e a Antología de mujeres poetas afrocolombianas (2010).

Cuesta e Ocampo, autores da Antología de mujeres poetas afrocolombianas (2010), corpus de estudo deste artigo, afirmam que a compilação foi feita com o objetivo de, além de "llenar un vacío en lo que respecta a la presencia y reconocimiento de poetas afrodescendientes en la producción literaria colombiana" (2010, p. 14), destacar o fenômeno subversivo dessas composições de Literatura Oral:

$$
\begin{aligned}
& \text { Afirmamos que estas poetas } \\
& \text { afrocolombianas están renovando y } \\
& \text { subvirtiendo con su obra un viejo canon de } \\
& \text { poesía [...] Ellas no solo recogen la tradición } \\
& \text { rítmica de la poesía que heredaron de }
\end{aligned}
$$


sus vertientes africanas, transmitida en forma oral y musical, sino que establecen una nueva perspectiva con su dicción, con su intención, con su transignificación. Así, articulan una nueva dinámica, con el eje concreto del propio texto del poema. (OCAMPO; CUESTA, 2010, p. 16)

A Antología de mujeres poetas afrocolombianas faz parte da "Biblioteca de Literatura Afrocolombiana", uma coleção de romances, contos, poesia, narração oral e ensaios representativos da literatura afro-colombiana, reunida em 18 volumes e publicada pelo Ministério da Cultura da Colômbia. O livro, que reúne a obra de 58 autoras de todo o país, e foi classificado por seus autores como a mais "abrangente e completa" compilação de escritoras afro-colombianas, está dividido em seis partes: As pioneiras, nascidas antes de 1940; Nascidas na década de 1940; Nascidas na década de 1950; Nascidas na década de 1960; Nascidas na década de 1970; e, finalmente, Nascidas na década de 1980.

Depois de fazer esta breve viagem pelas encostas da memória que convergem no mar ascendente das literaturas afro-colombianas, deve-se notar que esta pesquisa qualitativa, de natureza bibliográfica, visa identificar os elementos da memória coletiva das comunidades negras do Pacífico colombiano presente nos poemas coletados na Antología de Mujeres Poetas Afrocolombianas. 


\section{O PACÍFICO COMO “REGIÃO-MEMÓRIA"}

A escada de vozes que apelam à memória coletiva das comunidades negras para tecer os discursos ancestrais que constroem a identidade no Pacífico, se inicia com a escritora chocoana Luz Colombia Zarkanchenko. Nos poemas que integram a antologia, a escritora e ex-governante desenha uma janela para as paisagens marinhas do Chocó, em meados do século XX. Em "Allá van... Allá van..." e "La Bella", além de detalhar a geografia e os costumes de seu território, Zarkanchenko contesta as imagens negativas que historicamente têm mostrado esta região como uma terra inóspita de seres nus e incivilizados que não é chamada a fazer o país progredir (OLAYA, 2020).

Sua tinta transgressora também é vista em "Diosas del Alba", poema em que Zarkanchenko narra o trabalho de mães negras que se levantam cedo todos os dias a "buscar el maná entre la humedecida arena" e que, apesar do calor premente da selva chocoana, saem para coletar "el secreto salado de la escondida almeja", fonte de alimento para milhares de famílias naquela região empobrecida da Colômbia (2010, p. 84-85).

As riquezas culturais dos mundos negros situados nesta região são também o centro das criações de Bertulia Mina Díaz e Lucrecia Panchano, duas poetas caucanas, nascidas 
antes de 1940 que, como Zarkanchenko, colocam o Pacífico como o "lugar da memória" que inspira seus poemas. Isso se infere porque, segundo o antropólogo francês Paul Ricoeur, "as coisas lembradas estão intrinsecamente associadas aos lugares. Não é por engano que dizemos onde aconteceu o que aconteceu" (2007, p. 64).

En palabras de Ricoeur, estos "lugares de memoria" funcionan principalmente a la manera de los reminders, es decir, actúan como indicios de rememoración, que ofrecen sucesivamente un apoyo a la memoria que falla, esa vision de pasado endógeno de las comunidades subalternizadas y silenciadas que está en constante lucha contra el olvido, incluso una suplencia muda de la memoria muerta. En este sentido, estos lugares de rememoración permanecen como inscripciones, monumentos, potencialmente documentos, mientras que los recuerdos transmitidos únicamente por la vía oral vuelan como palabras que temen perderse entre las túpidas nieblas del olvido. (2007, p. 64)

O antropólogo Joël Candau complexifica a questão afirmando que a "memoria e a identidade se concentram em lugares, e em 'lugares privilegiados', quase sempre com um nome, e que se constituem como referências perene percebidas como um desafio ao tempo" (2018, p. 156). Nesse sentido, os poemas das autoras definem o Pacífico 
como a "região da memória", onde se afirma com força suas identidades (CANDAU, 2018, p. 157).

É assim que Bertulia Mina Díaz recorda as festividades, tragédias e acontecimentos que marcaram a sua vida em Santander de Quilichao - o seu "lugar de memória" - desde meados do século $X X$, município para o qual teve que se mudar, fugindo dos estragos da violência bipartidária que arrasou o norte do departamento de Cauca entre 1948 e 1953. Suas crônicas poéticas são rítmicas e refletem sobre os impactos do conflito armado nas festas populares, sem perder o rigor investigativo das salvaguardas da tradição oral das comunidades afro-pacíficas:

\author{
El torbellino en San Nicolás \\ En tiempos pasados \\ de algunas veredas \\ nunca les faltaba \\ músicos alegres. \\ [...] Cuando se iniciaban \\ algunos festejos \\ siempre había \\ honor a los viejos. \\ Cuando todo mundo \\ se hallaba prendido \\ cuatro hombres hechos \\ bailaban torbellinos [...]. \\ (MINA DÍAZ, B., 2010, p. 97)
}

Ressalte-se que o ato de enunciação dessa memória também é um ato de múltipla "re-existência", pois, como 
conclui Gayatri Spivak, se o subalternizado "não tem história e não pode falar", "a problemática da mulher parece a mais precária nesse contexto. Claramente, se você é pobre, de cor negra e mulher, será atingida triplamente [...] O subalterno como mulher está ainda mais profundamente na sombra" (1994, p. 83-90).

Nesse sentido, explicam Santos e Barbosa, esses atos de "re-existência" poética seriam uma forma de "resistir pela arte, de insistir em novas maneiras de viver e se colocar no mundo" (2020, p. 886). A literatura é então o bálsamo que ajuda as poetas, salvaguardas da memória coletiva, a curar suas feridas e a sobreviver à complexa realidade dos territórios do Pacífico colombiano. Assim, em cada verso são construídos espaços de existências, novas maneiras de ser e existir tendo a arte como instrumento de abertura para a realização que às minorias sociais almejam.

Do outro lado do mapa, Lucrecia Panchano, catalogada como uma das primeiras poetas tradicionais da região do Pacífico, além de depositar em seus escritos a memória coletiva do povo guapireño, usa a palavra recitada para questionar as estruturas hegemônicas de opressão que deixaram cicatrizes dolorosas nos corpos de mulheres e homens negros: 


\section{Carimba}

Carimba. Marca de abominable esclavitud que todo nos robó, excepto la conciencia que en nosotros releva su física presencia y enfatiza en el negro, su máxima virtud. [...] [...] Carimba... Ahora es símbolo de libertad y amor con un significado que el negro dignifica y es la expresión auténtica de ALTIVEZ Y VALOR.

(PANCHANO, 2010, p. 107-108)

Nas cinco estrofes que compõem a "Carimba", Panchano levanta seu grito de protesto para denunciar, seguindo a tradição de poetas como Candelario Obeso ou Manuel Zapata Olivella, os complexos modos de produção de hegemonias e subordinações nas construções identitárias observáveis nas populações afro-colombianas (ALVES; FERREIRA, 2016, p. 89). Sobre o uso da narrativa da memória como mecanismo de conexão com o continente africano, Lawo-Sukam explica que não seria um retorno físico, mas mítico, à África, pois o que se busca é celebrar uma herança ancestral que, paradoxalmente, se opõe à realidade adversa em que vivem há séculos os filhos da diáspora africana em América (2011, p. 41).

O uso de narrativas poéticas como espaço de luta e reescrita dos discursos hegemônicos na região do Pacífico também é visto na obra da maioria das poetas compiladas na antologia. $O$ exposto responde ao fato de que, segundo 
Graciela Maglia e Yves Moñino, nas comunidades afrocolombianas a Literatura Oral sempre atuou como "una estrategia de resistencia y cohesión socio-cultural que cumple una función ritual de reconexión con el tiempo ab origine de la fundación de la comunidad y tiene un contenido ético-didáctico en cuanto perpetúa la axiología comunitaria" (2015, p. 77).

Poetas caucanas nascidas na década de 1940 como Imelda Mina Díaz e Mary Grueso Romero, seguiram os caminhos narrativos de seus predecessores para compor histórias que hoje fazem parte da memória coletiva de suas comunidades. Em seus poemas, a palavra rimada torna-se uma ferramenta que ajuda a refletir sobre acontecimentos locais e nacionais, histórias de amor, desgosto, tragédias, entre outros (PEDROSA; VANÍN, 1994, p. 12). O exposto é exemplificado no poema "Sustento", texto em que Mina narra em detalhes o cotidiano de um fazendeiro do Norte do Cauca, seu "lugar de memória":

\author{
Sustento \\ Por el camino polvoriento, \\ taciturno y pensativo, \\ va un hombre a caballo \\ con sombrero de paja, \\ la ruana al hombro, \\ el machete en el cinto \\ con cubierta de cuero,
}


botas fuertes de cordones, medias y camisa de cuadros, pantalones de dril color café claro al despuntar la mañana. (MINA DÍAZ, I., 2010, p. 151)

É assim que, em versos curtos, a autora lembra que no passado as lavouras de laranja, pitahaya, mamão e sapote eram os únicos meios com que os camponeses daquela região - hoje atormentados por plantações ilícitas e intimidados pelo tráfico de drogas - obtinham sustento "para vivir y vestir bien / y a sus hijos educar" (MINA DÍAZ, I., 2010, p. 151).

Proteger a memória de seus ancestrais também se tornou um propósito de vida para Mary Grueso Romero, uma das vozes poéticas mais fortes do Pacífico colombiano. Segundo a escritora, a principal tinta de seus poemas sempre foi a lembrança de sua vida no Guapi, no Cauca, como ela confessou a Angela Olaya em entrevista publicada na revista Semana: "As rondas das crianças, a confecção de bonecas de pão, os batismos, os alabaos eram para construir a convivência pacífica entre as pessoas. Esses conhecimentos são o que reforço em minha poesia para que as pessoas se reconheçam em suas identidades negras" (OLAYA, 2019).

Os poemas de Grueso também se configuram como um manifesto anti-racista e feminista no qual converge discursos 
de resistência que buscam transformar ou "eu" em "nós" e ajudar a construir um ideal de comunidade, conforme afirma a autora em conversa com o jornalista Salvatore Laudicina:

A través de estos poemas, mis personajes recitan un discurso histórico que da cuenta del recorrido físico y social de la mujer negra del Pacífico Sur colombiano. [...] Las niñas y adolescentes negras de este tiempo tienen que conocer la lucha de género que hemos vivido. A mi parecer, eso es clave para el fortalecimiento de la identidad cultural. (LAUDICINA, 2016, p. 67)

Esta crítica pungente de Grueso ao sistema mundial capitalista, racista e cisheteropatriarcal é identificada do início ao fim em composições como "Pobreza negra":

\author{
Pobreza negra \\ Y cuando el negrito dispierte, \\ ¿quién lo alimentará? \\ Mi comadre la vecina \\ que esta randa' e mamá. \\ El negro no tiene compota \\ ni tetero pa' chupá. \\ Lo que tiene es un pellejo \\ que es la teta' e la mamá. \\ Jala jala mi negrito \\ la teta' e tu mamá, \\ el negrito jala y llora \\ porque na le bajará. \\ La mamá no tiene leche \\ porque en ayunas está \\ pero le bajará gota a gota \\ la sangre' e la mamá. \\ (GRUESO, 2010, p. 167-168)
}


Narrativas como a anterior dialogam com a análise de María Mercedes Jaramillo, que aponta que nos versos de Grueso "alegria e dor, humor e tragédia são misturados para explicar os altos e baixos da existencia, e a experiência de vida dos habitantes do Pacífico" (2007, p. 218). Assim, seus poemas mostram a "força espiritual dos afros que não perdem o desejo de aproveitar a vida apesar do abandono da região pelo Estado" (JARAMILLO, 2007, p. 217).

Os elementos narrativos acima mencionados são também fortemente percebidos na obra da poeta chocoana, Amalia Lú Posso. Em composições como "El galandro", em que narra as aventuras de Aristarco Perea, um "negro distinto", músico, "defensor de su tierra y enemigo de imposiciones y colonialismos" (POSSO, 2010, p. 172), a autora, seguindo o legado de suas predecessoras, aprimora a identidade e a diversidade dos homens e mulheres de seu território.

Em síntese, podemos dizer que num primeiro momento as produções poéticas feitas por mulheres afro-colombianas nascidas entre 1940 e 1950 se caracterizam por apelar à "memória forte", massiva, coerente, compacta e profunda que permite, como explica Joël Candau, “organizar significados, estruturar grupos humanos e construir identidades coletivas por meio de 'grandes narrativas'" (2018, p. 44). Seus versos 
também mostram como as formas poéticas ibéricas herdadas da colonização se consolidaram como um dos instrumentos da tradição oral do Pacífico que permite narrar o cotidiano, instruir filhos e netos, contar fatos reais, falar do divino e do humano (SUÁREZ, 2010).

\section{O FEMINISMO NEGRO DAS VOZES DA SEGUNDA METADE DO SÉCULO XX}

O florescimento das poetas afro-colombianos nascidas a partir de 1950, trouxe consigo a confirmação do "resgate da memória coletiva" como eixo temático do que hoje pode ser categorizado como a "Poesia Negra do Pacífico colombiano". No entanto, suas vozes também marcaram o nascimento de um movimento literário feminista que dialoga concomitantemente entre/com as encruzilhadas, de avenidas identitárias do racismo, do cisheteropatriarcado e do capitalismo (AKOTIRENE, 2019).

Autoras chocoanas como Laura Victoria Valencia e Sayly Duque Palacios, usam seus poemas como unguento para curar as feridas deixadas em seus corpos pela escravidão de seus ancestrais africanos. Além disso, reivindicam sua herança cultural e protestam contra as violações de direitos que as mulheres em sua região têm sido historicamente submetidas: 
El asiento del alma

Quién dice que el recuerdo no perdura. Quién dice que el pasado no es el guía. Quién sabe en qué lugar del pensamiento anida la memoria de otras vidas. Ya los barcos no surcan los mares como antaño, cargados de esclavos. Ya no hiere mi cuerpo, el látigo de tu ignorancia, pero aún... retumban en mi cabeza los quejidos... [...] [...] Quién sabe cuántas vidas he de vivir aún y... a cuántos mas perturbará este pasado de mis antepasados, de sus antepasados, antes de que... ipor fin!, venga el olvido y se asiente en el alma. [...] (VALENCIA, 2010, p. 195)

Nos poemas "El asiento del alma" e "Al cauce del río Atrato", Valencia estabelece um diálogo direto com sua herança africana e a memória de suas experiências de vida nas ruas úmidas de Quibdó, capital de Chocó. Segundo a poeta, é inevitável não ligar estes dois mundos porque é naquele território onde se preserva o maior número de tradições africanas na Colômbia: "Os escravizados e libertados pela força de seu próprio esforço e vontade, os preservaram e os mantiveram intactos graças à transmissão oral, como é feito na África" (CENTRO PANAFRICANO, 2015, s.p.).

E essa invocação à memória dos ancestrais escravizados também se lê nos poemas de Sayly Duque Palacios, que 
também imprime em seus escritos um grito de resistência feminista e negra:

Feliz día mujeres de la mina [...] iCompañeras de lucha y de infortunio! Alimentadas con coraje y trabajo rudo, hoy es el día nuestro, solo nuestro, de las que siembran flores para otros, de las que paren hijos, y otros crían, porque con lo que ganan el pan ya no se compra y sus senos vierten líquido lechoso, amargo, mezcla perfecta:

de pesticidas, cáncer, dolor: Tríptico desgarrador. ¡Ya no se pude más! [...] [...] Hoy es el día de aquellas que buscan y lloran a sus hijos, y la guerra cual pócima de horror, borró en ellos la aurora que nacía. [...] [...] ¿Qué hicimos compañeras? ¿Por qué nos persiguen? ¿Por qué nos acallan? Hoy es tu día, nuestro día, imi día! (DUQUE, 2010, p. 303-306)

O poema anterior ganha destaque no mar de escritos que fazem parte da Antología de mujeres poetas afrocolombianas, porque nele Duque Palacios questiona, a partir da perspectiva interseccional do feminismo negro, as estruturas interdependentes cruzadas por eixos do racismo, do patriarcalismo e do sexismo para explicar a vulnerabilidade em que as mulheres negras do Pacífico colombiano se encontram (AKOTIRENE, 2019): 
Las mujeres negras que habitan algunos territorios en Colombia padecen todo tipo de violencias. Esto, sumado al hecho de habitar lugares en donde el conflicto armado aún hoy permanece, o donde se están desarrollando conflictos ambientales o por la tierra y el territorio. Han sido víctimas directas de estos conflictos y han sufrido en su individualidad y en sus comunidades profundas violaciones a los Derechos Humanos y al Derecho Internacional Humanitario, por parte de todos los actores armados legales e ilegales. (CONFLICTO..., 2020, p. 2)

A problemática situação de violação de direitos vivida pelas comunidades afro-pacíficas também pode ser lida nos poemas de Felipa Trifenia Castillo Reina, outra integrante do grupo de poetas negras nascida na década de 1950. As histórias da autora de Tumaco, seguem à risca o legado estilístico herdado dos grandes narradores do Pacífico: seus versos são quadras octa-silábicas que narram desde histórias de amor até acontecimentos cotidianos de sua região:

\footnotetext{
Terror en Tumaco

En Tumaco sigue el terror con muerte todos los días, en el tigre y el panteón se encuentran cual gota fría.

Ayer cuando apareció

el primer muerto en la zona, preguntaban quién lo mató, hoy ya no vale una persona.
} 
Que pueblo tan conformista o es que todos tienen miedo, los matones como turistas cogiéndonos a todos del pelo.

Hasta ya comen junticos con algunos moradores, solo por tener miedito de estos agresivos señores. Parecen estar perdidos, la gente de la ciudad, por culpa de estos bandidos perdimos la dignidad. (CASTILLO, 2010, p. 314-315)

Consequentemente, podemos dizer que, em seus poemas, Laura Victoria Valencia, Sayly Duque Palacios e Felipa Trifenia Castillo Reina tornam-se "autoras-povo" que abraçam a palavra para falar de um problema generalizado em sua comunidade, e deixam de se comportar como sujeitos individuais para se tornarem sujeitos coletivos (FREJA DE LA HOZ, 2015). Da mesma forma, desafiam o silenciamento imposto aos negros e negras pelo sistema racista heteropratiarcal occidental, e buscam reafirmar os afros como narradores de seus próprios mundos.

Invocar o conceito de autor-povo implica referir-se ao que foi afirmado por Alfredo Freja de la Hoz, que descreve esse tipo de contador de histórias como grandes salvaguardas da memória coletiva das comunidades afro-colombianas (2015). Sua relevância reside no fato de que ao longo do 
tempo os trabalhos desenvolvidos por este sujeito coletivo podem se tornar um bem simbólico da literatura oral de sua comunidade:

De esta manera, la pérdida del reconocimiento del autor como individuo y el enriquecimiento de la obra en su proceso de tradicionalización en la literatura oral son elementos propios de la dinámica social del sujeto y del texto colectivo. La idea de sujeto colectivo en el campo de la literatura oral implica la despersonalización (transindividualización) del autor al momento de lanzar su obra al pueblo, y la idea de texto colectivo implica la apropiación de la obra por el pueblo. (FREJA DE LA HOZ, 2015, p. 136)

O vestido sagrado dos "autores do povo" também foi usado pelas poetas Julia Simona Guerrero e Paulina Cuero Valencia. A primeira escritora questiona em seus poemas a difícil realidade das mulheres pobres e rurais colombianas que perderam seus filhos devido ao conflito armado interno que subjugou o país por mais de meio século:

Lo que sucede en este país

Sucede en este país, en cada rincón de este país, una mujer da a luz para la vida, no para la guerra, no para la muerte.

(GUERRERO, 2010, p. 341-343) 
Paulina Cuero Valencia também abraça a palavra para denunciar em suas composições os terríveis efeitos que o racismo estrutural tem causado nas comunidades negras do Pacífico Sul colombiano: extrema pobreza, desnutrição, mortalidade infantil, deslocamento, falta de acesso à educação e aos serviços públicos básicos:

\section{El niño negro}

Hoy me encontré a mi niño negro, cruzando las esquinas, con su mirada triste, con sus ojos llorosos, me decía mil cosas en medio de sollozos, me pedía ayuda, me rogaba un beso.

El no tiene una escuela, su maestra ya no lo deja entrar; sus últimas palabras: "Ya no te aguanto más".

Y su peor delito nadie perdonará, haber nacido negro, eso y nada más. (CUERO, 2010, p. 533-535)

É importante destacar que a obra das poetas classificadas como "autoras-povo" ao longo deste texto, se baseia na história da memória das tragédias compartilhadas pelas comunidades negras do Pacífico para promover a construção de novos discursos identitários. Isso, segundo Candau, poderia ser explicado porque a memória dos sofrimentos "deixa traços compartilhados" por aqueles que "sofreram ou cujos parentes ou amigas tenham sofrido, modificando 
profundamente suas personalidades. A identidade historicizada se constrói em parte se apoiando na memória do sofrimento compartilhado" (2018, p. 151).

Nessa ordem de ideias, as "autoras-povo" da antologia, além de narrar a memória coletiva de suas comunidades, libertam-se das hierarquias raciais as quais os povos negros do Pacífico foram submetidos desde a colonização, ao notar as formações da consciência coletiva, que tanto se interseccionam a luta de classes, quanto denunciam "as dimensões ontológicas decorrentes da fabricação dos sujeitos raciais" (MBEMBE, 2018, p. 66).

Embora vozes mais contemporâneas como a nariñense, Maura Valentina González Quiñónez (Perla de Ébano), e a vallecaucana, María de los Ángeles Povov, também se destaquem por suas composições que apelam à memória para refletir sobre os meandros de suas vidas, seus poemas não poderiam ser chamados de "obras-povo" porque nas narrativas, compiladas na antologia, o sujeito não abandona seu espaço individual para se tornar coletivo. No entanto, deve-se destacar que, como a maioria das autoras que fazem parte do corpus de estudo, suas composições redefinem em cada palavra ou discurso identitário, o que representa ter nascido mulher e negra nesta conturbada região da Colômbia. Esses elementos ficam mais evidentes na obra da 
bonaverense, Sobeida Delgado Mina, que em poemas como "Negra soy" e "Afroamericana", busca abolir o pensamento colonial que vê e trata as mulheres negras como animais, marcadas sexualmente como fêmeas, mas, sem as características de feminilidade, porque "mulher feminina" só seria sinônimo de "mulher burguesa branca heterossexual" (LUGONES, 2008):

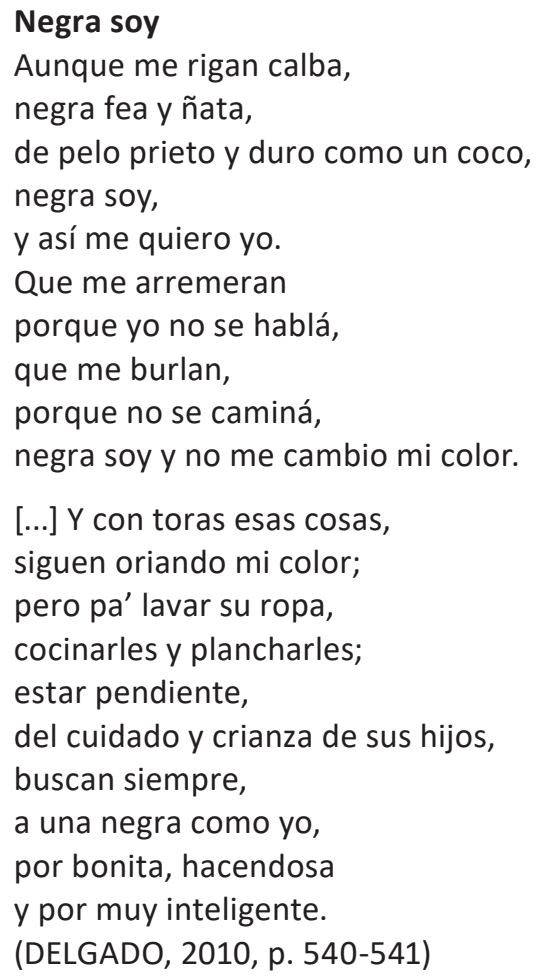

Em suma, podemos dizer que as poetas afro-colombianas nascidas na segunda metade do século $X X$, além de seguirem 
o caminho pavimentado de "autoras-povo" que desafiam o silenciamento dos historicamente subalternizados, apresentam em seus poemas um discurso que constrói e assume uma identidade de mulher afro-colombiana, e que ajuda a fortalecer as ideias identitárias da comunidade quando a memória da etnia a que pertencem se transforma em literatura (PALMEIRA, 2013). Da mesma forma, em seus versos de "re-existência" também são discutidas as complexidades das estruturas de gênero e estabelecidos diálogos que entendem o feminismo como escola de pensamento no qual ou binarismo homem e mulher surge como algo a ser superado (SANTOS; BARBOSA, 2020).

\section{CONSIDERAÇÕES FINAIS}

Depois de fazer essa viagem pelos caminhos das obras das poetas negras do Pacífico colombiano, podemos inferir que, em seus poemas, elas abraçam âncoras, nas quais todas as identidades se baseiam: a origem e o acontecimento (CANDAU, 2018). As autoras recorrem à veneração dos mundos ancestrais para dar sentido às suas comunidades negras, delineiam a "região-memória" como inspiradora de suas narrações, descrevendo as principais características socioculturais de seus mundos negros na tentativa de ratificar a estrutura identitária Afro-Pacífico. 
As "autoras-povo" compiladas neste artigo, ajudam a salvaguardar e construir a memória coletiva das comunidades negras do Pacífico colombiano por meio da narração de eventos trágicos, festivais ou acontecimentos do cotidiano que hoje fazem parte da visão do passado endógeno dessas comunidades, estabelecendo, assim, um diálogo com a história como forma de produção de conhecimento e formação de identidade.

Do mesmo modo, além de apropriarem-se das formas literárias ibéricas impostas pela colonização como forma de re-existir ante a dominação, as autoras afro-pacífico compiladas na antologia, principalmente as nascidas na segunda metade do século $X X$, questionam, desde a perspectiva do feminismo negro, as interfaces da diversidade de gênero, sexualidade, classe e geografias incorporadas de nosso sistema mundo ocidental.

\section{REFERÊNCIAS}

ACHUGAR, Hugo. Planetas sem boca: escritos efêmeros sobre arte, cultura e literatura. Tradução de Lyslei Nascimento.Belo Horizonte: Editora UFMG, 2006.

AKOTIRENE, Carla. Interseccionalidade. São Paulo: Sueli Carneiro; Pólen, 2019. ALVES, Alcione C.; FERREIRA, Rosa A. Diáspora e subalternidade na poesia de Lucrecia Panchano. Palimpsesto, n. 22, p. 85-101, 2016. Disponível em: https://docplayer.com.br/22677905-Diaspora-e-subalternidade-napoesia-de-lucrecia-panchano.html. Acesso em: 12 de jan. de 2020. 
ALZATE, Carolina. Mujeres, nación y escritura: no hablar, ni dar de qué hablar. In: CASTRO-GÓMEZ, Santiago (Ed.). Pensar el siglo XIX: cultura, biopolítica y modernidad. Pontificia Universidad Javeriana. Bogotá, p. 273-286, 2004.

CANDAU, Joel. Memória e identidade. Tradução de Maria Letícia Ferreira. São Paulo: Contexto, 2018.

CASTILLO, Felipa Trifenia. Terror en Tumaco. In: OCAMPO Z., Alfredo; CUESTA E., Guiomar. Antología de mujeres poetas afrocolombianas. Ministerio de Cultura. Bogotá, 2010. Disponibile en: https://babel. banrepcultural.org/digital/collection/p17054coll7/id/15/. Acceso en: 12 de dic. de 2020.

CENTRO PANAFRICANO. Entrevista a Laura Victoria Valencia. Revista Africanidad, 2015. Disponibile en: https://www.africanidad. com/2015/12/wanafrika-entrevista-laura-victoria_85.html. Acceso en: 10 de dic. de 2020.

CONFLICTO armado y múltiples violencias contra las mujeres negras y afrocolombianas. International Land Coalition, 6 de marzo 2020. Disponibile en: https://d3o3cb4w253x5q.cloudfront.net/media/ documents/RepDefensoras-Colombia-FINAL.pdf. Acceso en: 12 de dic. de 2020.

CUERO V., Paulina. El niño negro. In: OCAMPO Z., Alfredo; CUESTA E., Guiomar. Antología de mujeres poetas afrocolombianas. Ministerio de Cultura. Bogotá, 2010. Disponibile en: https://babel.banrepcultural.org/ digital/collection/p17054coll7/id/15/. Acceso en: 12 de dic. de 2020. DELGADO M., Sobeida. Negra soy. In: OCAMPO Z., Alfredo; CUESTA E., Guiomar. Antología de mujeres poetas afrocolombianas. Ministerio de Cultura. Bogotá, 2010. Disponibile en: https://babel.banrepcultural.org/ digital/collection/p17054coll7/id/15/. Acceso en: 12 de dic. de 2020. DUQUE, Sayly. Feliz día mujeres de la mina. In: OCAMPO Z., Alfredo; CUESTA E., Guiomar. Antología de mujeres poetas afrocolombianas. Ministerio de Cultura. Bogotá, 2010. Disponibile en: https://babel.banrepcultural.org/ digital/collection/p17054coll7/id/15/. Acceso en: 12 de dic. de 2020. 
FREJA DE LA HOZ, Alfredo. La literatura oral en Colombia. Romances, coplas y décimas en el Pacífico y el Caribe colombianos. Bogotá: Universidad Nacional de Colombia, 2015. GRUESO, Mary. Pobreza negra. In: OCAMPO Z., Alfredo; CUESTA E., Guiomar. Antología de mujeres poetas afrocolombianas. Ministerio de Cultura. Bogotá, 2010. Disponibile en: https://babel. banrepcultural.org/digital/collection/p17054coll7/id/15/. Acceso en: diciembre 12 de 2020.

GUERRERO, Julia Simona. Lo que sucede en este país. In: OCAMPO Z., Alfredo; CUESTA E., Guiomar. Antología de mujeres poetas afrocolombianas. Ministerio de Cultura. Bogotá, 2010. Disponibile en: https://babel.banrepcultural.org/digital/collection/p17054coll7/id/15/. Acceso en: 12 de dic. de 2020.

JARAMILLO, Mercedes María. Mary Grueso Romero: Poesía, Memoria e Identidad. In: ORTIZ, Lucía (Ed.). Chambacú, la historia la escribes tú: ensayos sobre cultura afrocolombiana. Bogotá: Editorial Iberoamericana, p. 217-232, 2007.

LAUDICINA R., Salvatore. Las muchachas se fueron de migraciones y sentires: Sobre poemas afrocolombianos que cuentan historias y construyen sujeto femenino. Universidad Autónoma de Occidente. Santiago de Cali, 2016.

LAWO-SUKAM, Alain. (A)cercamiento al concepto de la negritud en la literatura afro-colombiana. Cincinnati Romance Review: Afro-Hispanic Subjectivities, v. 30, 39-52, 2011. Disponibile en: https://scholar.uc.edu/ concern/articles/9k41zg13t?locale=en. Acceso en: 12 de dic. de 2020. LUGONES, María. Colonialidad y Género. Tabula Rasa, Bogotá, Colombia, n. 9, p. 73-101, julio-diciembre 2008.

MAGLIA, Graciela; MOÑINO, Yves. Oralitura de San Basilio de Palenque: temas europeos, africanos y criollos. Cuadernos de Literatura, Bogotá, v. XIX, n. 38, p. 171-201, julio-diciembre, 2015.

MBEMBE, Achille. Crítica da razão negra. Tradução de Sebastião Nascimento. São Paulo: N-1 Edições, 2018. 
MINA DÍAZ, Bertulia. El torbellino en San Nicolás. In: OCAMPO Z., Alfredo; CUESTA E., Guiomar. Antología de mujeres poetas afrocolombianas. Ministerio de Cultura. Bogotá, 2010. Disponibile en: https://babel.banrepcultural.org/digital/collection/p17054coll7/id/15/. Acceso en: 12 de dic. de 2020.

MINA DÍAZ, Imelda. Sustento. In: OCAMPO Z., Alfredo; CUESTA E., Guiomar. Antología de mujeres poetas afrocolombianas. Ministerio de Cultura. Bogotá, 2010. Disponibile en: https://babel.banrepcultural.org/ digital/collection/p17054coll7/id/15/. Acceso en: 12 de dic. de 2020. N'GOM, M'bare. Representaciones de la otredad: experiencia femenina e identidad en iNegras somos!. Cuadernos de Literatura, Bogotá, v. XIX, n. 38, p. 119-136, julio-dezembro, 2015.

NORA, Pierre (Org.). Les lieux de mémoire: La République. Paris: Gallimard, 1993.

OCAMPO Z., Alfredo; CUESTA E., Guiomar. Antología de mujeres poetas afrocolombianas. Ministerio de Cultura. Bogotá, 2010. Disponibile en: https://babel.banrepcultural.org/digital/collection/p17054coll7/id/15/. Acceso en: 12de dic. de 2020.

OLAYA, Ángela Yesenia. Mary Grueso: “Por qué me dicen morena? Si moreno no es color". Revista Semana, Bogotá, 2019. Disponibile en: https://www.semana.com/contenidos-editoriales/valle-del-cauca-latierra-sabe/articulo/mary-grueso-la-poeta-y-escritora-del-pacificocolombiano/630914/. Acceso en: 12 de dic. de 2020. OLAYA, Ángela Yesenia. El racismo contra el Pacífico y las comunidades afrocolombianas. La Silla Llena, Bogotá, junio 4, 2020. Disponibile en: https://lasillavacia.com/historias/historias-silla-Ilena/el-racismo-contrael-pacifico-y-las-comunidades-afrocolombianas/. Acceso en: 12 de dic. de 2020.

PALMEIRA, Francineide S. Escritoras na literatura afro-colombiana. Estudios de literatura Colombiana, v. 32, p. 87-102, 2013. PANCHANO, Lucrecia. Carimba. In: OCAMPO Z., Alfredo; CUESTA E., Guiomar. Antología de mujeres poetas afrocolombianas. Ministerio de 
Cultura. Bogotá, 2010. Disponibile en: https://babel.banrepcultural.org/ digital/collection/p17054coll7/id/15/. Acceso en: 12 de dic. de 2020. PEDROSA, Álvaro; VANÍN, Alfredo. La vertiente afropacífica de la Tradición Oral: géneros y catalogación. Universidad del Valle. Cali, 1994. PEREIRA, Danielle Cristina Mendes. Literatura, lugar de memória. SOLETRAS, v. 28, p. 344, 2014.

POSSO, Amalia Lú. El galandro. In: OCAMPO Z., Alfredo; CUESTA E., Guiomar. Antología de mujeres poetas afrocolombianas. Ministerio de Cultura. Bogotá, 2010. Disponibile en: https://babel.banrepcultural.org/ digital/collection/p17054coll7/id/15/. Acceso en: 12 de dic. de 2020. PRADO P., Nelly. El origen de los versos para enamorar: oralidad del Pacífico sur de Colombia. América Negra. Bogotá, Pontificia Universidad Javeriana, n. 12, p. 190-204, 1996.

RICOEUR, Paul. A memória, a história e o esquecimento. Tradução de Alain François. Campinas: Editora da Unicamp, 2007.

SANTOS, Allinne S.; BARBOSA, Adriana Maria de A. Literatura e reexistência: possibilidades do fazer literário como instrumento de ação e mudança social. Fólio Revista de Letras, v. 12, n. 1, 2020. Disponível em: https://periodicos2.uesb.br/index.php/folio/article/view/6176. Acesso em: 12 de dez. de 2020.

SUÁREZ, Félix. Etnoeducación: Tradición Oral y Habla en el Pacífico Colombiano. XIV Encuentro de Latinoamericanistas Españoles: congreso internacional. Santiago de Compostela, España, 2010, p. 2508-2534. Disponibile en: https://halshs.archives-ouvertes.fr/halshs-00532565/ document. Acceso en: 10 de oct. de 2020.

VALENCIA, Laura Victoria. El asiento del alma. In: OCAMPO Z., Alfredo; CUESTA E., Guiomar. Antología de mujeres poetas afrocolombianas. Ministerio de Cultura. Bogotá, 2010. Disponibile en: https://babel. banrepcultural.org/digital/collection/p17054coll7/id/15/. Acceso en: 12 de dic. de 2020.

ZAPATA OLIVELLA, Manuel. Las claves mágicas de América. Bogotá: Plaza Y Janés, 1989. 
ZARKANCHENKO, Luz Colombia. Allá van... Allá van... In: OCAMPO Z., Alfredo; CUESTA E., Guiomar. Antología de mujeres poetas afrocolombianas. Ministerio de Cultura. Bogotá, 2010. Disponibile en: https://babel.banrepcultural.org/digital/collection/p17054coll7/id/15/. Acceso en: 12 de dic. de 2020.

Julián Vivas Banguera

Mestrando (UESC).

Integra o "Grupo de Pesquisas em Interações Sócioambientais e Linguagem" (UESC).

http://lattes.cnpq.br/5328820206765927

https://orcid.org/0000-0003-1274-1503

julianvivasb@hotmail.com

Valéria Amim

Pós-doutora (Universidade da Beira Interior (UBI).

Professora de Comunicação Social e do Programa de Pós-graduação da Universidade Estadual de Santa Cruz (UESC).

Coordenadora do "Grupo de Pesquisa em Interações Sócioambientais e Linguagens" (UESC); pesquisadora do projeto de extesão "Núcleo de Estudos Afro-baianos Regionais - KÀWÈ (UESC).

http://lattes.cnpq.br/9397293014699124

https://orcid.org/0000-0001-8856-1889

vamim@uesc.br 